\title{
Sistema de proteção social brasileiro enquanto instrumento de combate à pobreza ${ }^{1}$
}

\author{
Lauro Francisco Mattei ${ }^{1,2}$ \\ https://orcid.org/0000-0002-1270-8052 \\ ${ }^{1}$ Universidade Federal de Santa Catarina, Centro Socioeconômico, Departamento de Economia e Relações Internacionais, Florianópolis, \\ SC, Brasil \\ ${ }^{2}$ Universidade Federal de Santa Catarina, Centro Socioeconômico, Programa de Pós-Graduação em Administração, Florianópolis, SC, \\ Brasil
}

\section{Sistema de proteção social brasileiro enquanto instrumento de combate à pobreza}

Resumo: Neste artigo discute-se a importância dos sistemas de proteção social (SPS) enquanto instrumentos de combate à pobreza e à exclusão social. Após fazer uma breve revisão sobre a trajetória desses sistemas no âmbito mundial, apresenta-se a evolução do SPS no Brasil, destacando-se a ausência da formação de um sistema completo, especialmente a partir da crise econômica da década de 1980 e do ideário neoliberal dos anos de 1990. Por fim, mostra-se que as propostas aprovadas recentemente pelo governo Temer se caracterizam como um retrocesso, não somente em termos de melhorias da proteção social no país, mas também em termos do futuro da nação.

Palavras-chave: Brasil. Pobreza. Sistema de proteção social.

\section{Brazilian social protection system as an instrument to fight poverty}

Abstract: This article discusses the importance of social protection systems (SPS) as tools to fight poverty and social exclusion. After a brief review of the history of these systems worldwide, the article presents the evolution of SPS in Brazil, highlighting the fact that the system has always been incomplete, particularly after the economic crisis of the 1980s and the neoliberal ideology guiding the policies during the 1990s. The study shows that the policies recently approved in President Michel Temer's government represent a setback regarding the improvements in social protection in the country and the future of the nation.

Keywords: Brazil. Poverty. Social protection system.

Recebido em 24.05.2018. Aprovado em 18.09.2018. Revisado em 17.01.2019.

(C) O(s) Autor(es). 2019 Acesso Aberto Esta obra está licenciada sob os termos da Licença Creative Commons Atribuição-NãoComercial 4.0 Internacional (https://creativecommons.org/licenses/by-nc/4.0/deed.pt_BR), que permite copiar, distribuir e reproduzir em qualquer meio, bem como adaptar, transformar e criar a partir deste material, desde que para fins não comerciais e que você forneça o devido crédito aos autores e a fonte, insira um link para a Licença Creative Commons e indique se mudanças foram feitas. 


\section{Introdução}

Os sistemas de proteção social foram implantados inicialmente em alguns países europeus com o objetivo de atender demandas sociais que cresciam com a expansão do sistema de produção capitalista, especialmente após a maturação da revolução industrial e consolidação da divisão social do trabalho. Tal sistemas se propuseram a disponibilizar um conjunto de serviços públicos com a função de melhorar a condição social das pessoas.

A trajetória desses sistemas é extremamente complexa, uma vez que incorporam ações e políticas nem sempre idênticas ao longo do tempo. Historicamente, pode-se mencionar as iniciativas inglesas das Poor Laws e os seguros sociais alemães do tempo de Bismarck até o moderno Estado de Bem-Estar Europeu do pósguerra que, de uma maneira geral, explicitam mais amplamente um conjunto de políticas públicas de proteção social. Isso significa a existência de diversas formas de construção e expansão de políticas, em sua maioria de cunhos sociais, e que pretendiam e buscavam ser universalizantes.

Desta forma, para se compreender melhor a trajetória das políticas brasileiras de proteção social, que sequer chegaram a formar um verdadeiro sistema de proteção, discute-se inicialmente a trajetória desses sistemas em termos mundiais e também no âmbito da América Latina. Além dessa breve introdução, o artigo é composto por mais três seções. A primeira delas trata de recuperar a trajetória geral dos sistemas de proteção no âmbito global e da América Latina. A segunda seção apresenta e discute a trajetória do sistema de proteção social no Brasil, destacando suas diferentes fases e impasses. A terceira seção contém as considerações finais do trabalho, enfatizando-se os retrocessos em curso promovidos pelo governo Temer.

\section{Notas sobre a trajetória dos sistemas de proteção social}

O ponto de partida para a constituição de sistemas de proteção social foi a adoção de medidas voltadas ao enfrentamento da pobreza, uma vez que entre os séculos XVII e XIX ser pobre era vergonhoso. Essa agenda se ampliou de tal forma que a partir do pós-guerra teve início a implementação da universalização dos serviços sociais. Essa passagem é importante, porque ela sedimenta a ideia de proteção social enquanto um direito dos cidadãos e não como serviços de caridade. Para tanto, esses sistemas deveriam assegurar serviços públicos de qualidade a todas as pessoas com necessidades.

Assim, verifica-se que a trajetória do sistema de proteção social nos países desenvolvidos promoveu uma articulação das políticas visando à reprodução de uma ordem social mais equilibrada, situação que ficou conhecida na literatura política como a ordem social-democrática. Nesse cenário, coube aos Estados disponibilizar os serviços sociais básicos e garantir o acesso aos mesmos por parte de todos os cidadãos.

Vianna (2002), buscando compreender as perguntas a quem proteger, como proteger e de que proteger, percebeu que as respostas a esses questionamentos por parte das nações foram historicamente diversas em função das estruturas político-institucionais das mesmas. Com isso, configuram-se modelos diferenciados de proteção social que podem ser resumidamente explicados a partir de três fases históricas, a saber:

a) Pobreza como foco: nesse período as ações governamentais ocorreram simultaneamente à expansão e consolidação dos estados nacionais, principalmente na Europa Ocidental. Num contexto de consolidação do modo de produção capitalista, a pobreza se tornou visível e passou a condicionar as ações governamentais por meio das chamadas leis dos pobres, que no fundo buscavam proteger a sociedade das ameaças representadas pela pobreza e pelos próprios pobres;

b) Foco no trabalho assalariado: ações para fazer frente aos riscos sociais oriundos do trabalho assalariado tornaram-se predominantes no sistema de proteção social, porém em um contexto econômico em que o capitalismo industrial já se encontrava consolidado. Essa fase, que teve início a partir do modelo alemão bismarckiano (1880), e que logo foi difundido por toda a Europa, se baseava no seguro social, cujo objetivo central era estabelecer o controle social, por parte dos estados nacionais, sobre o mundo do trabalho, porém sem sequer tocar nos problemas centrais da classe trabalhadora. Dessa forma, segundo a autora (VIANNA, 2002), a política social perdeu seu caráter assistencialista e ganhou um papel proativo no sistema de proteção, seja assegurando alguns direitos sociais, seja hierarquizando o universo dos beneficiários de acordo com as conveniências do sistema;

c) Do seguro para a seguridade social: as reformas realizadas pelos países desenvolvidos em seus sistemas de proteção social no pós-guerra apontaram na direção da universalidade como mecanismo de construção da cidadania. A partir de sistemas públicos universais buscou-se garantir os direitos sociais de todos os cidadãos, naquilo que ficou conhecido como Estado de bem-estar social. Nesse período, também conhecido como os anos dourados do capitalismo, ocorreu uma produção em larga escala, o consumo de massas e a expansão do emprego e dos salários, resultando numa maior homogeneidade social em algumas regiões do planeta. 
Há, ainda, outras interpretações sobre a trajetória dos sistemas de proteção social no âmbito mundial. Analisando esses sistemas a partir de suas abrangências e trajetórias, Esping-Andersen (1990) os categoriza em três grupos distintos:

a) Modelo Social-Democrata: sistema composto por diversos serviços públicos e de transferências monetárias com um caráter altamente inclusivo e universalista. O resultado é a constituição de sociedades bastante igualitárias e garantidoras da cidadania plena. Neste caso, cita-se como exemplo os países escandinavos;

b) Modelo Liberal: sistema assentado na lógica do trabalho onde se procura atender os indivíduos excluídos dos processos econômicos, razão pela qual as políticas assumem um caráter mais focalizado. Nesse caso, coexistem políticas de proteção social e índices importantes de desigualdades. Como exemplo desse modelo citam-se os casos dos Estados Unidos e dos países que compõem o Reino Unido;

c) Modelo Conservador: modelo cujos valores estão fortemente atrelados às concepções religiosas e com um menor grau de comprometimento com a erradicação das desigualdades, uma vez que nesse sistema procura-se preservar determinados privilégios sociais. Como consequência, as políticas públicas são bastante limitadas e os benefícios financeiros dependentes de contribuições pessoais e orçamentos governamentais. Destacam-se nesse modelo os casos da Bélgica e Áustria, dentre outros.

Em grande medida, concepções semelhantes também estiveram presentes em muitos países da América Latina, particularmente depois do período do pós-guerra, quando a industrialização avançou fortemente. Todavia, nessa região o sistema de proteção social, por ter sido implantado de forma imperfeita e incompleta, sequer chegou a se consolidar nos moldes anteriormente descritos, uma vez que não houve a universalização dos serviços prestados e nem a sua estruturação adequada no âmbito dos diferentes órgãos e instituições governamentais.

Mesmo diante de avanços observados em alguns países da região no sentido de construir um estado de bem-estar social (Argentina, Uruguai, Chile e Costa Rica), o que marca a trajetória latino-americana neste campo é a enorme heterogeneidade das sociedades conformadas nesse espaço geográfico. Levando esse aspecto em consideração, Draibe (1997) elaborou uma tipologia dos sistemas de proteção social na América Latina da forma como segue:

a) Sistema residual: representa um padrão pontual de intervenção da política social, cujo caráter é focalizado em indivíduos ou grupos de pessoas vulneráveis da sociedade, sendo que as intervenções tendem a cessar quando o problema se encontra superado;

b) Sistema meritocrático-particularista: parte-se do princípio de que as pessoas devem estar em condições de resolver suas necessidades via sua capacidade de trabalho. Porém, se reconhece a necessidade da política social para resolver problemas causados pelas distorções dos mercados. Neste caso, o sistema assume uma forma complementar às instituições econômicas e sociais;

c) Sistema institucional-redistributivista: esse sistema representa o reconhecimento de que o mercado não é capaz de ofertar bens e serviços sociais para todos os cidadãos. Daí a necessidade de políticas públicas de caráter social visando à garantia dos direitos das pessoas. Essa é a forma de proteção social que mais se aproximou do modelo de bem-estar europeu.

Como sabemos, a ordem socioeconômica latino-americana é bastante complexa, porém globalmente marcada pela questão da desigualdade social. Neste contexto, os sistemas de proteção social que foram implantados acabaram, em muitos países, ajudando a aprofundar essa desigualdade, uma vez que tendiam a proteger as categorias sociais melhor organizadas e dotadas de maior poder de barganha. Aliado a isso, as debilidades institucionais e organizacionais (alta centralização, limitada capacidade regulatória, baixo grau de participação da sociedade etc.) atuaram no sentido de reduzir a eficiência das ações desenvolvidas.

Esse cenário foi agravado nas duas últimas décadas do século XX pela grave crise econômica que afetou a maioria dos países do continente latino-americano. No bojo das reformas estruturais liberalizantes voltadas à superação da crise econômica em que se encontravam os países latino-americanos, ocorreram importantes reformas também nos sistemas de proteção social que, como vimos, sequer haviam sido consolidados.

Essas reformas, apoiadas por organismos internacionais - com destaque para o Banco Mundial - são distintas das anteriores, pois partem do pressuposto de que os sistemas de proteção social vigentes na região se esgotaram à luz de um conjunto de fatores que se explicitam de maneiras distintas nos vários países. Dentre esses fatores, destacam-se os déficits financeiros em vários setores; os problemas de gestão; a baixa eficácia dos programas sociais; a desestruturação do mercado de trabalho, com ampliação das formas precárias de trabalho (desemprego, informalidade, terceirização, contratação parcial etc.); os efeitos do crescimento demográfico etc.

A partir de então as políticas sociais integrantes do sistema geral de proteção latino-americano passam a ser comandadas pela premissa da racionalização e eficácia dos recursos, pela descentralização administrativa, pela terceirização de certos serviços para empresas privadas e pela focalização das ações públicas, em particular dos programas governamentais de combate à pobreza. É neste contexto que a América Latina se transformou no 
principal laboratório dos programas de transferência de renda, os quais se encontram presentes atualmente em dezenas de países e se transformaram rapidamente na principal estratégia de enfrentamento da pobreza.

\section{Sistema de proteção social brasileiro: dos primeiros atos à crise da década de 1980}

Algumas ações que hoje fazem parte do sistema de proteção social do Brasil já existiam desde a fundação da república, embora com formatos distintos. Todavia, um sistema mais organizado e planejado pelo Estado data de 1930, quando Vargas assumiu o poder no País. É a partir desse momento que os temas da saúde, educação, assistência, previdência e regulação do processo de trabalho passam a fazer parte da agenda governamental sequencialmente.

Segundo Matijascic (2015), o atendimento do sistema se dava de forma diferenciada, uma vez que a extensão da cobertura e a disponibilidade de serviços ocorriam em função da categoria socioprofissional a qual o trabalhador era integrado à luz da legislação vigente. Nesse caso, o reconhecimento dos direitos sociais era um ato de iniciativa exclusiva do poder executivo federal. $\mathrm{O}$ resultado é que os benefícios e seus respectivos valores dependiam do poder de barganha de cada categoria. É desta época a criação dos Institutos de Aposentadorias e Pensões (IAPs) que pagavam benefícios e disponibilizavam assistência médica.

A esse processo Santos (1981 apud MATIJASCIC, 2015, p. 9) denominou:

[...] de cidadania regulada, uma vez que o Estado se antecipou às demandas populares e as categorias socioprofissionais, em vez de buscarem conquistas trabalhistas de forma solidária, competiram entre si pelo acesso a serviços e pelo que foi considerada uma prerrogativa concedida a cada uma delas, não assumindo o formato de uma luta coletiva por direitos sociais, de forma similar à observada, por exemplo, na Europa Ocidental.

Nesse período inicial, observa-se que muitas categorias de trabalhadores foram excluídas do sistema, com destaque para os trabalhadores rurais, trabalhadores domésticos, trabalhadores por conta própria etc. Este foi um longo percurso que somente seria modificado integralmente na Constituição de 1988, com a adoção do capítulo específico sobre direitos sociais.

O sistema de proteção social com características mais universais no Brasil ${ }^{2}$ começou a ser construído no período do pós-guerra, ganhando relevância durante o regime militar a partir do ano de 1964. No entanto, a política social brasileira sempre esteve subordinada às estratégias de desenvolvimento do país, especialmente durante o regime militar, quando houve expansão dos gastos públicos na esfera social e o sistema de proteção permaneceu atrelado à lógica da política macroeconômica geral (HENRIQUE, 1999).

O período entre 1964 e 1988 ficou conhecido como a estratégia conservadora porque combinava a expansão da oferta de bens e serviços com a centralização do processo decisório e com a regressividade dos mecanismos de financiamento, processo este assentado no uso quase que exclusivo de recursos de natureza fiscal (FAGNANI, 1997). Nesta lógica, o caráter redistributivo do sistema ao longo de quase três décadas foi bastante limitado. De certo modo, este é um fato que ajuda a explicar os elevados índices de concentração de renda no respectivo período.

A centralização do processo de decisão na esfera do Governo Federal foi favorecida pelo regime político militar, o qual impediu que organizações de representação da sociedade tivessem qualquer participação ou envolvimento na definição e condução das políticas sociais. Assim, a ausência de participação política e a falta de controle social possibilitaram ao Estado a adoção de um sistema que, com o passar do tempo, foi sendo tomado por interesses particulares e clientelistas, com impactos negativos sobre os próprios resultados das políticas sociais.

Este modelo de intervenção estatal começou a se esgotar na década de 1980. Contribuíram para isso a crise financeira internacional que teve fortes repercussões no País e o próprio esgotamento político do regime militar. Segundo Fagnani (1999), o agravamento da crise econômica na década de 1980 potencializou as demandas sociais, ao mesmo tempo em que restringiu o espaço das ações governamentais. Com o retorno do País à normalidade política, permitiu-se que demandas sociais voltassem à agenda pública, especialmente entre 1986 e 1998, quando se discutiu e foi elaborada a atual Constituição do País.

\section{Do neoliberalismo da década de 1990 aos dias atuais}

A Constituição Federal de 1988 contém um capítulo específico sobre a Seguridade Social, compreendendo ações relativas à saúde, previdência e assistência social, ficando sob responsabilidade do Estado a 
organização desse sistema. Além disso, definiu-se como princípios orientadores do mesmo a universalidade da cobertura; a equivalência dos benefícios e dos serviços às populações urbanas e rurais; a diversidade das formas de financiamento; e a introdução de mecanismos democráticos de gestão.

Especificamente na esfera financeira, definiram-se como fontes de financiamento do sistema nacional de seguridade social as contribuições dos empregados e dos empregadores, o Fundo de Investimento Social (FINSOCIAL) ${ }^{3}$, a parcela dos lucros líquidos das empresas ${ }^{4}$, a receita percentual de jogos, além das parcelas dos impostos arrecadados pelos governos federal, estaduais e municipais.

Todavia, o processo de implantação desse novo sistema de seguridade social foi marcado pela fragmentação política da Aliança Democrática ${ }^{5}$, pelo clientelismo político e pela corrupção. O somatório desses fatores teve efeitos diretos sobre a eficácia das políticas sociais adotadas posteriormente à Constituição de 1988, uma vez que seus resultados até o final do século XX continuaram sendo bastante limitados. Este fato, somado à continuidade da crise econômica, corroborou para que a exclusão social e a pobreza atingissem índices elevadíssimos durante a década de 1990.

Para Paiva e Mattei (2009), embora a atual Constituição seja portadora de avanços consideráveis frente à história brasileira, as mazelas do legado das desigualdades sociais e dos longos períodos de crise na economia revelaram-se em obstáculos reais para sua implementação. A isso se soma, ainda, o contínuo processo de contrarreformas que se transforma em ameaça real aos avanços contidos na Carta Suprema.

A década de 1990 iniciou com o Governo Collor (1990-1992) ${ }^{6}$, o qual concentrou seu ataque à presença do Estado na vida econômica e social. É o neoliberalismo a la brasileira sendo implementado a partir das forças políticas conservadoras e de falsas promessas às massas de excluídos socialmente ${ }^{7}$. $\mathrm{Na}$ área social criou-se obstáculos ao funcionamento dos direitos sociais outorgados pela Constituição de 1988, ao mesmo tempo em que se procurou adiar a implementação da legislação complementar que garantisse aqueles direitos sociais.

Além disso, conforme afirma Marques (1992), leis como a de número 8.213/1991 acabaram gerando distorções no sistema de financiamento da seguridade social, uma vez que se permitiu que recursos desta rubrica passassem a ser mais uma fonte de custeio do Estado brasileiro, ou seja, recursos da seguridade social passaram a financiar despesas orçamentárias diversas do próprio Governo Federal.

A estabilidade econômica obtida durante o Governo Fernando Henrique Cardoso (FHC), entre 1995-2002, esteve ancorada fortemente nos preceitos do ajuste econômico proposto pelo Consenso de Washington, em que a desregulamentação dos mercados, a liberalização comercial e a reforma do Estado figuravam como elementos centrais. A partir daí estavam dadas as condições para as reformas nos programas de seguridade social, uma vez que a retomada do crescimento econômico e as mudanças no papel do Estado foram consideradas essenciais para se obter melhorias na esfera social.

Registre-se que nesta lógica emergiu, ainda em 1995, a contradição central na definição das políticas sociais, uma vez que passaram a se confrontar duas posições antagônicas. Por um lado, a concepção embasada na tradição universal que consagra os direitos à saúde, educação, previdência e assistência social como direitos inalienáveis dos cidadãos, tendo o Estado como portador desses benefícios e, por outro, a concepção neoliberal que enfatizava os princípios da seletividade e da focalização dos gastos públicos junto às camadas mais necessitadas da população.

É neste contexto que o Governo FHC lançou, em 1996 (BRASIL, 1996b), uma estratégia de desenvolvimento social para o país. Nela nota-se a existência de um grupo de políticas que visava introduzir políticas focalizadas para enfrentar as "situações agudas de fome e de miséria" (BRASIL, 1996b, p. 20). Para tanto, as políticas de combate à pobreza deveriam "focalizar suas ações com base em critérios técnicos de necessidades e de eficácia" (BRASIL, 1996b, p. 20-21, grifo do autor), visando a descentralização e a articulação entre as diferentes esferas governamentais (federal, estadual, municipal) (BRASIL, 1996b). 
O modelo implementado nos anos 1990 é antagônico às orientações constitucionais. Paulo Netto (1999) demonstra que o projeto político-econômico conduzido no País nas últimas décadas não exclui a política social, mas a situa numa perspectiva inteiramente diversa daquela que está inscrita na Constituição de 1988. O projeto em curso interdita a costura e a concretização de políticas sociais capazes de efetivamente restringir a voracidade do capital. Nesse aspecto, a política social passa a ser inteiramente subordinada à orientação macroeconômica que, por sua vez, é constituída de acordo com os ditames do grande capital. O autor complementa afirmando que o projeto político da grande burguesia brasileira, sintonizado com a mundialização, não exclui a vigência de políticas sociais. $O$ que ele exclui é uma articulação de política social, pública e imperativa, cujo formato tenha como suposto um Estado que ponha limites políticos democráticos à lógica do capital, que tenha por eixo uma função democrático-reguladora em face do mercado.

Quanto menos equidade mais privilégios; é o esperado. Assim, contingentes expressivos são deixados à deriva do mercado, ou da suposta benemerência familiar, ou da comunidade solidária para fazer jus a alguma proteção social, em geral precarizadas em termos de qualidade dos serviços e de alcance das medidas. De acordo com o princípio da discriminação negativa, da segmentação dos usuários, setores particularistas paulatinamente vão se apropriando de fatias discrepantes do fundo público, diante da ausência de políticas públicas universalizadoras dos direitos sociais, ao sabor de uma agenda visivelmente impopular (PAULO NETTO, 1999).

No bojo desta concepção geral começaram a ser implementados os primeiros programas de transferências de renda no Brasil a partir de 1997, período em que se verifica uma forte incompatibilidade entre os programas de ajuste macroeconômico do País e as estratégias de desenvolvimento social do Governo FHC (FAGNANI, 1999). Em grande medida, essa incompatibilidade ocorreu devido ao fato de que as constantes restrições ao crescimento econômico do período tiveram efeitos negativos sobre a esfera social, fragilizando as fontes de financiamento do sistema de seguridade e ampliando a exclusão social da população pobre.

As primeiras experiências com programas de transferência de renda no Brasil precederam os programas do Governo Federal e ocorreram inicialmente apenas em algumas localidades (HALL, 2008; INSTITUTO DE PESQUISA ECONÔMICA APLICADA, 2008; ROCHA, 2008; SOARES; SÁTYRO, 2009). Essas experiências pioneiras, especialmente nos municípios de Campinas e Ribeirão Preto, estavam mais assentadas na filosofia de garantia de uma Renda Básica de Cidadania (RBC), a qual se constitui, segundo seus principais defensores ${ }^{8}$, num dos caminhos mais eficientes para se erradicar a pobreza.

Posteriormente, inspirados nas experiências pioneiras de Campinas, de Ribeirão Preto e do Distrito Federal, esses programas passaram a se proliferar por diversas regiões do país (LAVINAS, 1998). No entanto, este processo ocorreu de forma atabalhoada e sem as condições técnicas operacionais e financeiras que a implantação deste tipo de política exigia (ROCHA, 2008). Com isso, muitas dessas experiências foram sendo abandonadas nos anos seguintes.

$\mathrm{Na}$ esfera do Governo Federal os primeiros programas de transferência de renda surgem no ano de 1997 no âmbito do Programa Comunidade Solidária9 (BRASIL, 1995), o qual procurou promover reformas profundas na política social (saúde, educação, previdência, habitação e assistência social), visando focalizar o gasto público e aumentar sua eficiência, num ambiente de ajustes macroeconômicos que se opunham à expansão do gasto governamental na área social.

Todavia, o ambiente macroeconômico do período impôs restrições à ação do governo no âmbito das políticas sociais. Assim, entre 1995 e 1998, enquanto as despesas financeiras da União (juros, encargos e amortizações da dívida pública interna e externa) aumentaram de $37 \%$ para $58 \%$, os gastos sociais passaram de $25,5 \%$ para $26 \%$ (FAGNANI, 1999). Este fato ajudou a consolidar ainda mais a visão da focalização das ações e dos gastos governamentais na esfera social ${ }^{10}$.

Segundo Fagnani (1999), o modelo institucional e operacional deste tipo de política social foi inspirado em experiências de outros países que também adotaram programas sociais compensatórios para minimizar os efeitos negativos das políticas de ajuste macroeconômico e de reforma do Estado que foram implementadas a partir dos anos de 1990, especialmente na América Latina.

Dessa forma, o Brasil, juntamente com o México, foi o país da América Latina que rapidamente passou a fazer uso das políticas focalizadas de transferência de renda como mecanismo de combate à pobreza no bojo das reformas dos programas sociais. Isto explica o fato desse país deter a maior cobertura de beneficiários e um dos maiores percentuais de gasto em toda a região.

No início do Governo Lula (março de 2003) foi criado no âmbito do Ministério de Desenvolvimento Social e de Combate à Fome o Cartão Alimentação - que correspondia ao programa cupom de alimentos na versão original do Programa Fome Zero (PFZ) - também com o objetivo de transferir renda para parcelas da população que se encontravam em estado de insegurança alimentar e nutricional.

Em outubro de 2003 foi criado o programa Bolsa Família (BRASIL, 2004), com o objetivo de unificar todos os programas sociais de transferência de renda já existentes anteriormente (Bolsa Escola, Bolsa Alimenta- 
ção, Cartão Alimentação e Auxílio Gás). Além desse objetivo geral, o programa pretendia dar maior agilidade ao processo de liberação mensal dos recursos financeiros às famílias necessitadas, bem como reduzir os entraves burocráticos e facilitar o sistema de controle de recursos, visando aumentar sua transparência junto à sociedade. De uma maneira geral, o programa Bolsa Família articula-se a partir de três aspectos básicos: ampliação dos serviços de saúde, educação e nutrição, através dos mecanismos de condicionalidades; integração dos programas de transferência de renda com os demais programas de assistência e proteção social; e busca da superação direta da pobreza através da focalização das transferências monetárias decorrentes das ações governamentais.

De um modo geral, segundo Paiva e Mattei (2009, p. 185):

[...] as ações ainda permanecem sob o império da despolitização e operadas pela perda de vínculo de classe destas políticas públicas com as disputas históricas da sociedade. Por um lado, não se combate a destinação dos recursos públicos ao velho sistema de privilégios e, por outro, não se assegura a alocação adequada de recursos para ações de erradicação das desigualdades sociais. Dessa forma, configura-se uma ação política governamental ambígua, que oscila entre o plano humanitário e uma versão ainda estigmatizadora da pobreza.

Em grande medida, isso ocorre porque as ações e iniciativas no campo social, embora tenham sofrido uma expansão expressiva na última década, ainda estão longe de revelar uma articulação definitiva entre as esferas econômica, política e social que seja capaz de enfrentar e vencer o pensamento conservador que naturaliza a pobreza e a exclusão social, condenando seguidamente as iniciativas de expansão do investimento público implementadas no sentido de fortalecer e garantir os direitos sociais assegurados na Carta Magna do país.

\section{Considerações finais}

Ao longo do texto vimos que a trajetória de implementação do Sistema de Proteção Social caminhou no sentido de promover melhorias nas condições de vida da população, especialmente da classe trabalhadora. Assim, foram constituídos em várias partes do mundo, particularmente no pós-guerra, sistemas que foram capazes de atender as demandas sociais da população pobre, de tal forma que a pobreza e a exclusão passaram a ter uma tendência regressiva.

No caso brasileiro nota-se a lenta trajetória de organização de um sistema mínimo de proteção social forjado até a década de 1980. A partir desse período, a crise econômica, por um lado, e a ideologia neoliberal, por outro, colocaram em xeque até mesmo os desígnios do capítulo dos Direitos Sociais presentes na Constituição de 1988. Com isso, verificamos que um sistema com características universalizantes não conseguiu ser estabelecido no país, além do que os problemas de financiamento desse sistema permaneceram recorrentes, ao mesmo tempo em que a diversidade de demandas sociais do país não pôde ser atendida.

É nesse contexto que deve ser compreendida a ação do governo Temer que visa reintroduzir no cenário nacional a concepção de Estado Mínimo. A Emenda Constitucional 95 (BRASIL, 2016b), aprovada pelo Congresso Nacional em 2016, é o maior exemplo de regressão social, uma vez que congela os gastos primários do governo (saúde, educação, assistência social, cultura, esporte, defesa nacional etc.) por um período de vinte anos, o que significa, na prática, o adeus ao desenvolvimento social do País. Isto porque estima-se que para os próximos 10 anos (2016-2025), somente nas áreas de saúde e educação, deverá ocorrer uma redução dos gastos per capita da ordem de $6 \%$. O fato é ainda mais grave se considerarmos que o ritmo de crescimento populacional, segundo o Instituto Brasileiro de Geografia e Estatística (2018), deverá ser de $0,8 \%$ ao ano nesse período, o que significa que mais de 20 milhões de pessoas estarão demandando serviços sociais governamentais.

Além disso, a mudança constitucional atingiu fortemente a política de valorização do salário mínimo que estava em curso no país desde 2004. Com isso, busca-se desvincular as correções do salário mínimo das taxas de crescimento do Produto Interno Bruto (PIB), como forma de reduzir as despesas previdenciárias e assistenciais e, ao mesmo tempo, garantir o aumento das taxas de lucros das empresas. Na prática, essas medidas irão reduzir efetivamente o poder de compra da classe trabalhadora e, em consequência, provocar a ampliação da desigualdade social.

Na sequência da aprovação da Emenda Constitucional 95 (BRASIL, 2016b), o governo Temer encaminhou ao Congresso Nacional a proposta de reforma da previdência social (BRASIL, 2016a), ao mesmo tempo em que aprovou uma reforma trabalhista (BRASIL, 2017) que apenas retira direitos dos trabalhadores. Todas essas propostas remontam ao debate do início dos anos de 1990, quando vigorava a tese do Menos Estado e Mais Mercado. Ao final daquela década vimos o desastre social que tomou conta do País, uma vez que parcelas expressivas da população foram colocadas à margem da sociedade. 
É nesta direção - e diante dos fatos políticos recentes - que reconhecemos a existência de um grande retrocesso, não somente em termos de desarticulação de um sistema de proteção social que sequer veio a se constituir adequadamente, mas especialmente em termos do futuro da nação.

\section{Referências}

BRASIL. Câmara dos Deputados. Proposta de Emenda à Constituição PEC 287/2016. Altera os arts. 37, 40, 109, 149, 167, 195,201 e 203 da Constituição, para dispor sobre a seguridade social, estabelece regras de transição e dá outras providências. [Brasília, DF], 5 dez. $2016 \mathrm{a}$. Disponível em: https://www.camara.leg.br/proposicoesWeb/fichadetramitacao?idProposicao=2119881. Acesso em: 15 mar. 2018.

BRASIL. [Constituição (1988)]. Emenda Constitucional no 95, de 15 de dezembro de 2016. Altera o Ato das Disposições Constitucionais Transitórias, para instituir o Novo Regime Fiscal, e dá outras providências. Diário Oficial da União, Brasília, DF, 16 dez. $2016 \mathrm{~b}$. Disponível em: http:/www.planalto.gov.br/ccivil_03/Constituicao/Emendas/Emc/emc95.htm. Acesso em: 15 mar. 2018.

BRASIL. Decreto $n^{\circ} 1.366$, de 12 de janeiro de 1995. Dispõe sobre o Programa Comunidade Solidária e dá outras providências. Diário Oficial [da] República Federativa do Brasil, Brasília, DF, 13 jan. 1995. Disponível em: http://www.planalto.gov.br/ccivil_03/decreto/ 1995/D1366.htm. Acesso em: 15 mar. 2018.

BRASIL. Lei ${ }^{\circ} 10.835$, de 8 de janeiro de 2004. Institui a renda básica de cidadania e dá outras providências. Diário Oficial da União, Brasília, DF, 9 jan. 2004. Disponível em: http://www.planalto.gov.br/ccivil_03/_Ato2004-2006/2004/Lei/L10.835.htm. Acesso em: 15 mar. 2018.

BRASIL. Lei $\mathrm{n}^{\mathrm{o}}$ 10.836, de 9 de janeiro de 2004. Cria o Programa Bolsa Família e dá outras providências. Diário Oficial da União, Brasília, DF, 12 jan. 2004. Disponível em: http://www.planalto.gov.br/ccivil_03/_Ato2004-2006/2004/Lei/L10.836.htm. Acesso em: 15 mar. 2018.

BRASIL. Lei ${ }^{\circ} 13.467$, de 13 de julho de 2017. Altera a Consolidação das Leis do Trabalho (CLT), aprovada pelo Decreto-Lei n 5.452 , de $1^{\circ}$ de maio de 1943, e as Leis $n^{\text {os }} 6.019$, de 3 de janeiro de 1974, 8.036, de 11 de maio de 1990, e 8.212, de 24 de julho de 1991, a fim de adequar a legislação às novas relações de trabalho. Diário Oficial da União, Brasília, DF, 14 jul. 2017. Disponível em: http:// www.planalto.gov.br/ccivil_03/_Ato2015-2018/2017/Lei/L13467.htm. Acesso em: 15 mar. 2018.

BRASIL. Lei n ${ }^{\circ}$ 8.742, de 7 de dezembro de 1993. Dispõe sobre a organização da Assistência Social e dá outras providências. Diário Oficial [da] República Federativa do Brasil, Brasília, DF, 8 dez. 1993. Disponível em: http://www.planalto.gov.br/ccivil_03/LEIS/ L8742.htm. Acesso em: 15 mar. 2018.

BRASIL. Lei n ${ }^{\circ}$ 9.394, de 20 de dezembro de 1996. Estabelece as diretrizes e bases da educação nacional. Diário Oficial [da] República Federativa do Brasil, Brasília, DF, 23 dez. 1996a. Disponível em: http://www.planalto.gov.br/ccivil_03/LEIS/L9394.htm. Acesso em: 15 mar. 2018.

BRASIL. Presidência da República. Uma estratégia de desenvolvimento social. Brasília: Presidência da República, 1996b. (Coleção documentos da Presidência da República).

DRAIBE, S. M. Uma nova institucionalidade das políticas sociais? Reflexões a propósito da experiência latino-americana recente de reforma dos programas sociais. São Paulo em Perspectiva, São Paulo, v. 11, n. 4, p. 3-21, 1997.

ESPING-ANDERSEN, G. Three worlds of welfare capitalism. New Jersey: Princenton University Press, 1990.

FAGNANI, E. Política social e pactos conservadores no Brasil: 1994-1992. Economia e Sociedade, Campinas, v. 6, n. 1, p. $183-238$, jun. 1997. FAGNANI, E. Ajuste econômico e financiamento da política social brasileira: notas sobre o período 1993-1998. Economia e Sociedade, Campinas, n. 13, p. 155-178, dez. 1999.

HALL, A. Brazil's Bolsa Família: a double-edged sword? Development and Change, The Hague, v. 39, n. 5, p. 799-822, Sept. 2008. HENRIQUE, W. O capitalismo selvagem: um estudo sobre desigualdade no Brasil. 1999. Tese (Doutorado em Ciências Econômicas) Instituto de Economia, Universidade Estadual de Campinas, Campinas, 1999.

INSTITUTO BRASILEIRO DE GEOGRAFIA E ESTATÍSTICA. Projeções da população: Brasil e unidades da federação: revisão 2018. 2. ed. Rio de Janeiro: IBGE, 2018. (Relatórios metodológicos, v. 40).

INSTITUTO DE PESQUISA ECONÔMICA APLICADA. Pobreza e mudança social. [Brasília, DF]: IPEA, 22 set. 2008. (Comunicado da Presidência, n. 9. Pnad 2007: primeiras análises, v. 1).

LAVINAS, L. Programas de garantia de renda mínima: perspectivas brasileiras. Rio de Janeiro: IPEA, out. 1998 (Texto para discussão, n. 596).

MARQUES, R. M. Previdência social: a nova legislação e as propostas de reforma de governo. São Paulo: Fundap, 1992. (Texto para discussão, 4).

MATIJASCIC, M. Política social brasileira: conquistas e desafios. Brasília, DF: IPEA, mar. 2015. (Texto para discussão, 2062).

PAIVA, B. A.; MATTEI, L. Notas sobre as políticas sociais no Brasil: a primeira década do século XXI. Revista Textos \& Contextos, Porto Alegre, v. 8, n. 2, p. 175-194, jul./dez. 2009.

PAULO NETTO, J. FHC e a política social: um desastre para as massas trabalhadoras. In: LEUSBAUPIN, I. (org.). O desmonte da nação: balanço do governo FHC. Petrópolis: Vozes, 1999. p. 75-89.

ROCHA, S. Transferências de renda federais: focalização e impactos sobre a pobreza e a desigualdade. Revista de Economia Contemporânea, Rio de Janeiro, v. 12, n. 1, p. 67-96, jan./abr. 2008. 
SUPLICY, E. M. Renda de cidadania: a saída é pela porta. São Paulo: Cortez: Fundação Perseu Abramo, 2002.

SOARES, S.; SÁTYRO, N. O programa Bolsa Família: desenho institucional, impactos e possibilidades futuras. Brasília, DF: IPEA, out. 2009. (Texto para discussão, n. 1424).

VIANNA, M. L. T. W. Em torno do conceito de política social: notas introdutórias. Rio de Janeiro: [s. n.], dez. 2002.

\section{Notas}

1 Artigo previamente publicado nos Anais do $5^{\circ}$ Encontro Internacional de Política Social e $12^{\circ}$ Encontro Nacional de Política Social, ocorridos na cidade de Vitória, Espírito Santo, entre os dias 5 e 8 de junho de 2017.

2 As ações governamentais se concentravam, basicamente, nas áreas de saúde, educação, assistência social, suplementação alimentar e programas habitacionais.

3 A partir de 1991 o Fundo de Investimento Social (FINSOCIAL) desaparece e em seu lugar criou-se a Contribuição para o Financiamento da Seguridade Social(COFINS).

4 Na Constituição de 1988 isto foi denominado de Contribuição sobre o Lucro líquido (CLL).

5 Coalizão de forças políticas que deram sustentação ao Governo Sarney (março de 1985 a março de 1990), o qual implementou as primeiras políticas sociais oriundas da nova Constituição.

6 Este mesmo movimento se repete no governo temporário de Itamar Franco (1993-1994).

7 Um dos slogans do Governo Collor era a defesa dos descamisados (leia-se: dos pobres).

8 No Brasil o Senador Eduardo Suplicy (Partido dos Trabalhadores) é o principal expoente desta corrente, tendo escrito um livro clássico sobre o assunto (SUPLICY, 2002), além de ter conseguido aprovar, em 2004, um projeto de sua autoria que instituiu no País a RBC (BRASIL, 2004).

9 O programa Comunidade Solidária era o nome do programa guarda-chuva que englobava toda a política social do Governo Fernando Henrique Cardoso elaborada em 1996 no âmbito da estratégia de desenvolvimento social (BRASIL, 1996b). Uma correlação pode ser feita ao programa Fome Zero do Governo Lula, do qual o programa Bolsa Família é uma das ações.

10 Registre-se que no primeiro período do Governo Cardoso foram aprovadas a Lei de Diretrizes e Bases da Educação Nacional (LDB) (BRASIL, 1996a) e implementada a Lei Orgânica da Assistência Social (LOAS) (BRASIL, 1993), que já tinha sido aprovada em 1993.

\section{Lauro Francisco Mattei}

1.mattei@ufsc.br

Doutorado em Economia pelo Instituto de Economia da Universidade Estadual de Campinas (Unicamp)

Professor Titular do Departamento de Economia e Relações Internacionais e do Programa de Pós-Graduação em Administração da Universidade Federal de Santa Catarina (UFSC)

\section{UFSC}

Campus Universitário Reitor João David Ferreira Lima - Trindade

Florianópolis - Santa Catarina - Brasil

CEP: 88.040-900

\section{Agência financiadora \\ Não se aplica.}

\section{Contribuições dos autores}

Não se aplica.

\section{Consentimento para publicação}

Não se aplica.

\section{Conflito de interesses}

Não há conflito de interesses.

Aprovação por Comitê de Ética e consentimento para parti-

cipação

Não se aplica. 